\title{
Explore the Short Video's Technology in E-commerce in India
}

\author{
doi : https://doi.org/10.32628/IJSRCSEIT
}

Tanmayee Tushar Parbat ${ }^{1}$, Rohan Benhal ${ }^{2}$, Honey Jain ${ }^{1}$, Dr. Vinayak Musale ${ }^{3}$

1B.E IT, Dr. Vishwanath Karad MIT World Peace University, Pune, Maharashtra, India

${ }^{2}$ BBA IT, Dr. Vishwanath Karad MIT World Peace University, Pune, Maharashtra, India

${ }^{3}$ Dr. Vishwanath Karad MIT World Peace University, Pune, Maharashtra, India

\begin{abstract}
Article Info

Volume 7, Issue 6

Page Number: 276-284

Publication Issue :

November-December-2021

Article History

Accepted : 05 Dec 2021

Published : 15 Dec 2021

In this paper, there is description of videos technology has been used widely as well as tried to explore the transform in the structure of selling as well as buying of the product mainly in short videos. With the emergence of the Internet, online procedure are replacing conventional models in our society. Even so, not many recognize the criticality required in E-commerce industry. Video commerce is the next great thing of marketing. It connects to a web page of a dealer selling or giving services rightly from its portal to the consumers. They use a digital shopping cart structure and permit payment by credit card, debit card or electronic fund transfer payments. The E- commerce services helps in decreasing costs in managing orders while also interacting with a broad range of suppliers as well as trading partners. It also requires any type of business transaction in which the parties interconnect electronically rather than by physical exchanges or direct physical contact.

Keywords :- E-commerce, digital shopping cart, physical contact
\end{abstract}

\section{INTRODUCTION}

The way we consume video online has evolved so fast, it's made my head spin. Online videos featuring products and brands actually help by rising smartphone penetration, the launch of $4 \mathrm{G}$ networks and increasing consumer wealth, the Indian ecommerce market is expected to grow to US\$200 billion by 2026 from US\$ 38.5 billion in 2017 [1]. Online retail sales in India are expected to grow by 31 per cent to touch US\$32.70 bill Consumers make purchasing decisions online. Modern-day consumers have grown to rely on video in their online shopping. Video In 2014, consumers who viewed video were up to 3.3 times more likely to make online purchases. This is especially true for consumers who shopped from online-only retailers [2, 3]. The demand for video product reviews, tutorials, how-to's, unboxing, and comparison videos was especially high during the 2014 winter holiday period when most gift purchases occurred. Here are some interesting facts that need attention:

- Mobile video consumption is almost doubling with every passing year.

- By 2020 video traffic will represent around 80$90 \%$ of the global consumer internet traffic. 
- $80 \%$ of all web traffic will be contributed by videos the e-commerce has transformed the way business is done in India.

The Indian e-commerce market is expected to grow to US\$ 200 billion by 2026 from US\$ 38.5 billion as of 2017. Much growth of the industry has been triggered by increasing internet and smartphone penetration [4]. The ongoing digital transformation in the country is expected to increase India's total internet user base to 829 million by 2021 from 636.73 million in FY19. India's internet economy is expected to double from US\$ 125 billion as of April 2017 to US\$ 250 billion by 2020, majorly backed by ecommerce. India's E-commerce revenue is expected to jump from US\$ 39 billion in 2017 to US\$ 120 billion in 2020, growing at an annual rate of 51 per cent, the highest in the world [5].

\subsection{Market Size}

Propelled ion in 2018, led by Flipkart, Amazon India and Paytm Mall. Smartphone shipments in India increased eight per cent year-on-year to reach 152.5 million units in 2019, thereby making it the fastest growing market of the top 20 smartphone markets in the world. During 2018, electronics is currently the biggest contributor to online retail sales in India with a share of 48 percent, followed closely by apparel at 29 percent investments/ developments [6, 7].
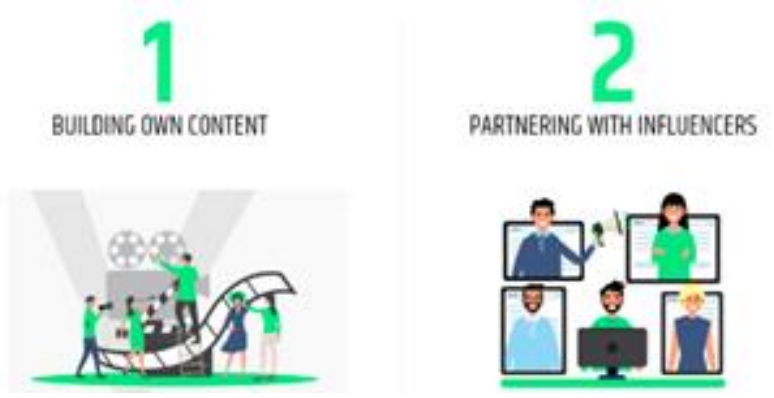

Figure 1: Way to Start Video Marketing

Explainer videos in E-commerce in India
- As of June 2018, Google is also planning to enter into the E-commerce space by November 2018.

Some of the major developments in the Indian Ecommerce sector are as follows:

- In January 2020, Divine Solitaires launched its E-commerce platform.

- In the Union Budget of 2020-21, government has allocated Rs 8,000 crore (US\$ 1.24 billion) to BharatNet Project, to provide broadband services to 150,000-gram panchayats.

- In August 2019, Amazon acquired 49 per cent stake in a unit of Future Group.

- Reliance to invest Rs 20,0000 crore (US\$ 2.86 billion) in its telecom business to expand its broadband and E-commerce presence and to offer $5 \mathrm{G}$ services [8].

- In September 2019, PhonePe launched superapp platform 'switch' to provide a one stop solution for customers integrating several other merchants apps.

- In November 2019, Nykaa opened its 55th offline store marking success in tier II and tier III cities.

- Flipkart, after getting acquired by Walmart for US\$ 16 billion, is expected to launch more offline retail stores in India to promote private labels in segments such as fashion and electronics. In September 2018, Flipkart acquired Israel based analytics start-up Upstream Commerce that will help the firm to price and position its products in an efficient way $[9,10]$.

- As of March 2019, Flipkart launched its internal fund of about US\$ 60-100 million to invest from early stage to seed innovations related to ecommerce industry.

- Paytm has launched its bank - Paytm Payment Bank. Paytm bank is India's first bank with zero charges on online transactions, no minimum ment and free virtual debit card. India is expected to be its first market [11]. 
- Reliance retail is going to launch online retail this year. It has already launched its food and grocery app for beta testing among its employees.

\section{OBJECTIVE OF RESEARCH}

In India E-commerce has so far covered a vast market in urban as well as rural areas of India and in order to increase the market, sales and profit margin companies are using short video's to attract the customer in which they are able to show all the details of products which not only attract the customer but also, saves the money of the particular product companies.

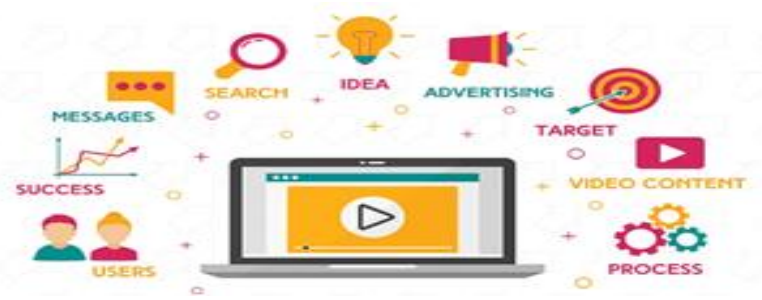

Figure 2: Video Marking

The cause for the analysis of the E-commerce while using short video is to see how much growth $\mathrm{E}$ commerce is doing with the help of short video and how much utilization product manufacturing are funding in covering all advertisements such as motion graphic animation, multi merchant Ecommerce technologies, multiple explainer videos which not only helps to saves times but also with the small span of duration they describe the similar product characteristics more clearly as well as many more manufacturing are using short video even pharmacy industry market place motion graphics animation.

\section{LITERATURE REVIEW}

In the Business Intelligence area, Mikacic I et al. (in 2012) give her work with regard to $B I$ which shows its concepts, elements, methods and advantages.
Companies have realized the significance of enforcing attainment of the aim confined by their business policies by business intelligence concepts.

Min, $\mathrm{Y}$ et al. (in 2011) inaugurates his work regarding BI in the hospitality services. They mention to the significance of BI in the hospitality areas. They further shows how BI can give out as an obstacle to competitive pressures and talk about later potential harnessed by BI that are not yet chief stream but are anticipate changing the industry.

Richard et al. (in 2011) demonstrate an architecture for mobile marketing in the area of android; spreading by business intelligence. He supervise a bibliographic study in order to figure out a structure architecture scheme which permits to collect information from social networking as well as achieve data mining over existent data marts in a industries to search customer likings and propose tailored advertisements.

Tariszka et al. (in 2014) demonstrate a literature analysis in social Business Intelligence as a testing agenda. The span of BI and social media has now shows meanwhile crucial research areas. As the motive of $\mathrm{BI}$ is to hold up organizational recommendations by presenting relevant analytical data, the social media have become an important source of individual as well as personal knowledge point of view, also the views of stakeholders.

Todi et al. (in 2012) Issued his technical analysis related his establishment to Business Intelligence. He described the $\mathrm{BI}$ as: the processes, tools and tools needed to turn data into details and details into knowledge and knowledge into ideas that drive money -making business plan of action.

Trkman (in 2010) Issue his paper in the journal 'Communications of the Association for Information Systems'. He shows a vision to help to make it better the timeliness and standard of inputs to the judgmental process. His BI framework has segmented the importance of the unstructured data and debated the emerge requirement to launch BI tools for its gaining, cleanup, combination, findings, analysis, and carriage. 
Vuksic et al. (in 2013) Inaugurate a case study to request $\mathrm{BI}$ in magazine distribution his case talk about the use of business intelligence structure in the present and maximizing of magazine distribution by a UK company. The case study increases a number of issues which are considered. It demonstrates the variation of forces which are driving industries to acquire business intelligence structure.

Ranjan et al. (in 2009) suggest some critical elements of BI. They recognize the effective elements of BI in order to support the assessment of the BI in an ITbased company. They further recognized the effective elements of BI by a case study which is based on a broad ranging analysis of current literature.

Carlos et al. (in 2017) demonstrate a categorization of EC data while using data mining. This work talk about the evolution of an tools for both consumers and industries, which would make use of details currently available on EC websites to categorize the data in accordance with the quality of the products obtainable.

Guo et al. (in 2019) define the tools of EC in business with their obstacles and anticipation. The work talks about the reality of global EC and pointed out structural risk areas that could pressurize the system. It scrutinizes the connection between globalization and EC adoption or obtaining that lead the way to finer business presentation and efficacy.

During the research of E-commerce structure, we have attempted to see the system when no Ecommerce activities were taking on.

\subsection{Consumer Behavior}

When we talk about E-commerce video production, the absolute video length span is around 1-2 minutes. It may appear effortless to generate a short-form video, but it is not that easy, Just, same as other any other videos, you will be needed to well defined on the factors and the factors more than the length [12, 13].

Furthermore, a video which runs for a minute or two is still recommended to those that run on longer period. There are a number of causes why you need to examine short-form videos in your content master plan and to assist you to recognize what are these causes.

\subsection{E-commerce Video Production and the Power of Short-form Videos}

People's attention spans are short: - The standard human attention duration is becoming lesser and shorter as social media carry on governing the globe of visual occurrences. This fact is a sign that shortform videos are more advantageous than longer ones. Thus, it is not important easier to explain messages and which leaves an effect on your observers in the small span of time [14].

Short-form videos can be used in a multiple ways. You can show teasers, tryout reels, product videos, branded content, and many more ideas with the help of short-form videos. As long as your video liked by the viewers and the intension of the video is served with viewers, it will automatically connects you will have a better chance to change their area of interest towards your products or goods $[15,16]$.

Short-form videos are cost-effective:- If we talk about ecommerce video production, shorter videos are cheap contrast to longer videos. Editing of short videos is quiet easy which takes only few supplies to complete. And more over in a small span of time short videos are more expressive and can convey message correctly.

Short-form videos are more social media friendly: Whether we like it or not, social media plays a crucial part in present - businesses. In case of ecommerce video manufacturing, if you want your videos to beneficial from the multiple social media platforms, make them in such a way that they are very simple and sweet is one method to do it. Video dispensation platforms have their limits [17].

Thus, if you want to transfer a marketing video on Facebook, Twitter, Instagram, Snap chat, YouTube, 
etc., you required to take advantage on making your videos as small as feasible [18].

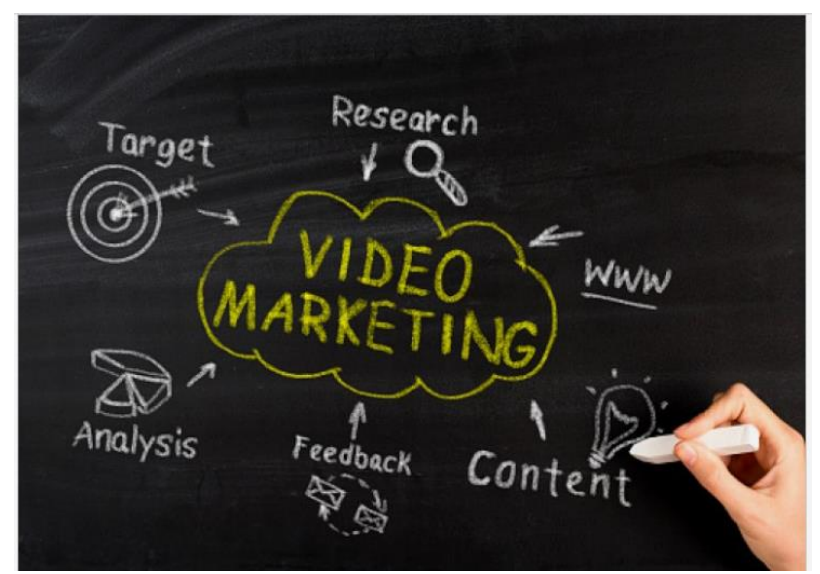

Figure 3: India Video Marketing Market

As we all know that we all understand that, "A picture is worth 1,000 words." But did you know that your brain literally operates videos 60,000 times speedy than text?

In a cramped, direct to customer's areas, video can be griped as a precious mode to assist and generate connections, as well as assist in e-commerce industries stand out to their target consumers $[19,20]$.

\subsection{Video can be a Tactic to Convert Visitors Once they Land on Your Site}

With the handling customers are leading, there are callers that are focusing to be sold or leased involved prior to be sold. For instance, if you're E-commerce site is selling red low-tops, then review hosting a video of an engaging human race on a beach with red low-tops. This imagination can pull out an entire new set of emotions which can't be measured in an unchanged catalog format [21]. Not to describe this will represent your consumers the more attempts you've made to capture him or her. Even though the artistic discernment of your website will differ through the board based on a visitor's earlier shopping occurrences and assumptions, it's crucial to note that a site's design, color palette as well as company will every time require to add up for the consumers, mainly as they choose whether to eventually to make a buy [22]

\section{METHODOLOGY}

The analysis is formally based on the two dissimilar methods of carry out the functioning of commerce i.e. conventional and electronic commerce. The study mostly based on:-

- Study of standard method of commerce.

- Study of currently method of commerce i.e. ECommerce

- Relative study of conventional commerce with contemporary ecommerce

- Security warning of E-commerce

- Study of E-commerce in the region of assurance

- Reasonableness study of using E-commerce in the field of short videos

- Presently framework of E-commerce in short videos

- Disadvantages (if any) of make use of Ecommerce in short videos

- Obstacles of E-commerce in short videos

- Recommendations for evolution of E-commerce in short videos

- Hereafter of E-commerce (especially in short videos)

There is no appropriate method to form a product video. It's all up to on your vertical; consumers have multiple assumptions on what they want to see. And, they have multiple requirements based on how they make purchasing resolution. There are a few things though those are usual to all the pre product videos out there.

They tell a story: In the absence of effective context, making product video is not possible. You could generate loads of product videos for your product page that just represent the list of things in a 360 degree spin. But, what's the idea in disbursing the money to generate a video which can really use for multiple reasons. Your video requires to be branded. 
It requires put your product or service in context. That frequently means it requires to be represent in use, as a great instances of your product and why the consumers can't repel it. Use the video to carry on with re-iterating on your brand usefulness importantly, a how to video that can be reuse all over your merchandise.

They are short: Object to make a video surpassing out at 30 seconds mainly for the purpose of viral on social media. Yes, it's difficult to refine a communication down to half a minute, but the superb product videos make it look like an easy. Few of the videos below go over this limit, but pay notice to circumstances. Some viewers divisions will be ok with more video length if you're engaging on other emotional lines.

They are human: The view of a product adaptor video is to raise relate-capability between your brand and your consumers. Text and pictures don't get this across as well. You want capability consumers to walk away feeling as though you appreciate them, and talk to the base of their best self.

\section{The Power of Video on ecommerce Websites: -}

To repudiate the potency of product videos is to go in opposition some well analysis marketing bias. While an ecommerce website can triumph without video, to waste precious chances is not compatible with a solid ecommerce marketing plan you would be taking much higher possibility avoidable to deny less dependable policies. There is a beyond doubts requirement for online videos in marketing, even with the present scenario of the market. Let's face it; our brains are anxious to answer mostly to optical stimuli. Our optical sense gives most of our ruling auditory input, and thus it plays a crucial role in the emergence of point of view. This is not just science jargon; it is a reality that maximum Americans pay out $85 \%$ of their online time seeing videos. Same as statistics can be set up throughout, and there is connection between consumer's interest and the visual medium is framed. If that does not give you with sufficient inducement, examine the reality that search engines are much pleasant to videos in balancing to other put in. By far, the most favored hunt engine in present is Google. Its algorithm dictates that it should prioritize outcome that have comprise video in their content. It clearly favors multimedia outcomes rather of bland text. If you balance to suitable develop your product video, it will be much undemanding for people to mark your content online. Proceeds into account that Google also possess the most demanded video hosting site (YouTube), it is a marketing goldmine to tackle the reach of this marvelous platform.

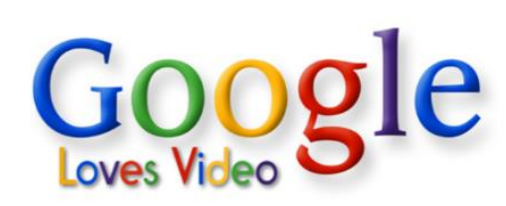

Figure 4: Video on Ecommerce Websites

People just don't like to read when options are obtainable. Data free from the two social media and ecommerce sites represents a rise in public attentiveness for posts that comprise music, images or videos. YouTube and Facebook are mainly effectual at collecting data, due to the reality that they both have a non-segregated voting structure. Not only are videos more gripping on an individual stages, but they also get divide a lot more. It has acquired to the point where important industries have attempt to stage growing videos and recreate their success. Cost is other reason. A few decades ago, to air a business on television could evaluate tens of thousands of dollars. Possess a video commercial was an advantage reserved for the very rich. Nowadays, this chance is dirt cheap and reachable; it would be an indignity to misspend it. The closing point is mostly the most effective, as it is a disagreement of come before. If perceive trust, serve to say, you might want to see on every side and be astonished by just how many 
industries (including competitors) are manufacturing of ecommerce websites and ready to use product videos. Forming product videos is a relatively cheap cost, low risk funding that assure an out of proportion of came back on that financing.

\section{DATA ANALYSIS}

Video is a very effectual structure of content and its demand has gone hand-in-hand with the rise of social media. Thus, the reality that so many of us use online videos on a day to day basis, many agents still aren't using video as bit of their digital marketing policies or aren't seeing the best outcomes.

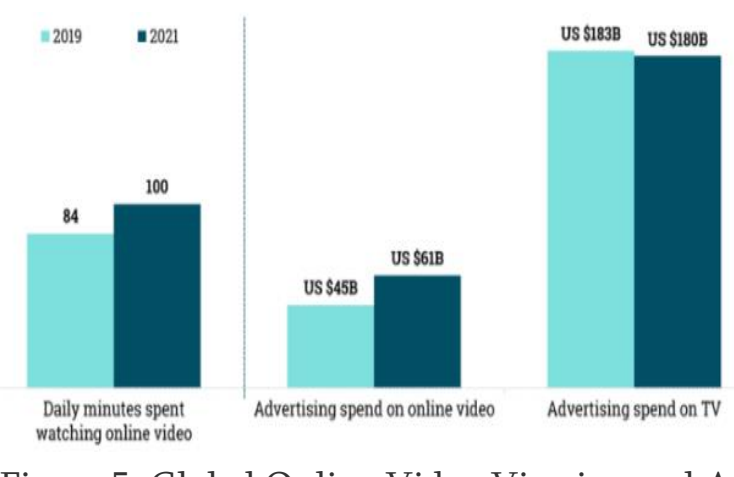

Figure 5: Global Online Video Viewing and Ad Spending Forecast

In $2020,92 \%$ of marketers said that video is a crucial role of their marketing policies. This has raise from $78 \%$ in 2015, describing that the significance of video is only expanding. So what is it that form video so crucial? Well, as stated $88 \%$ of marketers, video marketing gives them with positive return on capital. When you review that at most 33\% said the similar in 2015, it represents that customer emotions in connection with videos is much powerful now.

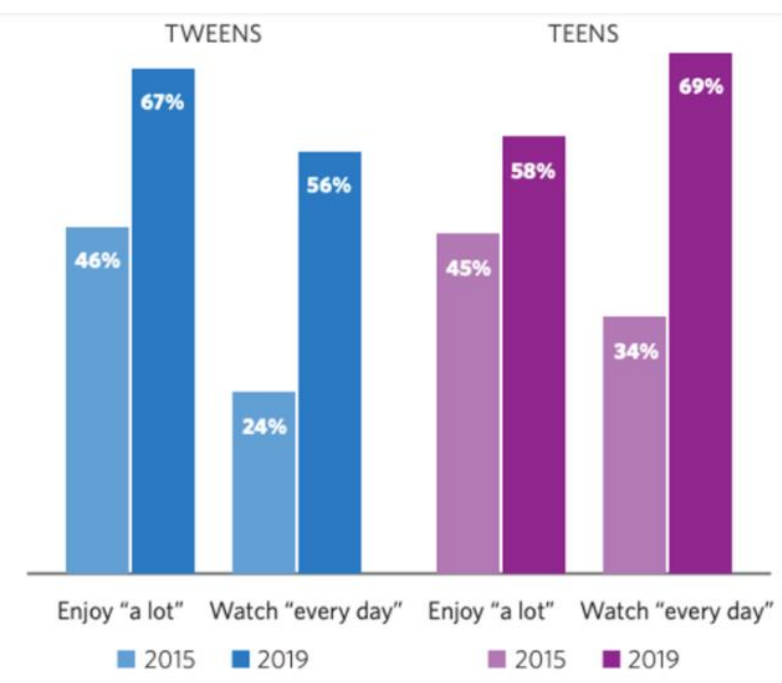

Figure 6: Online Video Viewing: Frequency and Enjoyment, by Age 2015 vs. 2019

$66 \%$ of US teens see online videos on day to day basis. Online videos are purely of attentiveness to younger statics with $66 \%$ of teens that is $13-19$-year-olds and $56 \%$ of tweens that is 8-12-year-olds in the US analysis that they see videos online on day to day basis. This describes higher rise in video observing for these age break as contrast to 2015 .

\section{CONCLUSION}

Video is a strong business by business to business industries in order to rise as well as transformation. In reality, $41 \%$ of business to business marketers are keen in survey how actually to consumer tool, mostly when groups with social media, it is mostly used more videos can be attach to their marketing as well as sales policies in 2020. And with the help of such videos being an excellent method to describe product details, making use of them all over the purchase tour can assist to additionally certify business to business sales leads. It's also important notice that $22 \%$ of B2B companies are keen in survey the chance given by podcasting and live streaming, recommending that there may be chances in these fields too. The increase of social media has described that there are several categories of videos to share than ever prior too. As an outcome, $57 \%$ of 
marketers have been assisting live video with the time span of policies. Over a third (34\%) of marketers are using Facebook's live streaming choices, generating in-the-short time videos that will permit audience to behave in real-time manner. Instagram social media is the second major demanded choice, with $13 \%$ generating live videos on the platform. Live videos are an effectual process to generate conversations and create a group on every side of your brand. Thus, they may not be potential for every mode of business, so it is valuable evaluating what your contenders are performing and analyzing what your viewers' needs.

\section{REFERENCES}

[1] Mikacic I. and Dulcic Z, 2012, Implementation of the Process Approach and Business Process Management Concept in Croatian Shipyards, International conference of Knowledge management and learning (MakeLearn), Slovenia.

[2] Min, Y., Shin, Y., Jeehong, K., Kim, D., Kang, S., 2011, Business Process Performance Management Using Bayesian Belief Network, 1st International Conference on Computers and Industrial Engineering, University of Southern California, Los Angeles, USA.

[3] Richard, G S., 2011, An Empirical Study of BIbased Corporate Performance Management in North America and East Asia,

[4] A Renaissance of Information Technology for Sustainability and Global Competitiveness. 17th Americas Conference on Information Systems, AMCIS 2015, Detroit, Michigan, USA,

[5] Tariszka-Semegine, E., Organizational internal communication as a means of improving efficiency, European Scientific Journal, Vol. 8, No.15, (Retrieved from http://eujournal.org/ on November 2014).

[6] Todi A., Agrawa A., Taparia A., Lakhmani N., and Shettar R., 2012, Classification Of ECommerce Data Using Data Mining,
International Journal of Engineering Science and Advanced Technology Vol.2, No.3.

[7] Trkman, P., 2010, the critical success factors of business process management. International Journal of Information Management. Elsevier, Vol 30, No. 125.

[8] Vuksic V. B., Bach M. P., and Popovic, A., 2013, Supporting performance management with business process management and business intelligence: A case analysis of integration and orchestration. International Journal of Information Management, 33(4).

[9] Ranjan J., 2009, Business Intelligence: Concepts, Components, Techniques and Benefits, Journal of Theoretical and Applied Information Technology, Vol 9, No 1.

[10] Raza F., 2011, Evaluating E-commerce Strategy Development for Organizations: A Literature Review, Journal of Business Studies Quarterly, Vol. 7, No. 2.

[11] Rezaei, S., and Alikhani, A., 2014, An assessment on employees' business intelligence and CRM on customer satisfaction: A case study of Auto industry, Management Science Letters, $4(2)$.

[12] Rouhani, S., Asgari, S., and Mirhosseini, S. V., 2012, 'Review Study: Business Intelligence Concepts and Approaches', American Journal of Scientific Research, 50.

[13] Sarathi P., Saha A., and Begum S., 2012, The application of E-commerce in Business Application: Their Problems and Prospects, International Journal of Computer Applications, Vol. 49, No. 10.

[14] Carlos, O.; Raquel G.; Carlos, F. Facilitating imaginations through online product presentation videos: effects on imagery fluency, product attitude and purchase intention. Electron. Commer. Res. 2017, 17, 661-700.

[15] Carlos, F.; Raquel, G.; Carlos, O. The influence of online product presentation videos on persuasion and purchase channel preference: 
The role of imagery fluency and need for touch.

Telemat. Inform. 2017, 34, 1544-1556.

[16] Guo, H.L.; Zhao, Y.; Shi, H.Y. Research of the influence of short-form video display on customers' purchase intention on the $\mathrm{e}^{-}$ commerce platform. Inf. Stud. Theory Appl. 2019, 42, 145-151.

[17] Nisbett, R.E.; Ross, L. Human Inference: Strategies and Shortcomings of Social judgment; Prentice Hall Inc.: Eanglewood Cliffs, NJ, USA, 1980; doi:10.2307/2184495.

[18] Dong, D.H.; Liu, S.N.; Jin, Y.F.; Qi, H. An empirical research on E-commerce customer website loyalty. In Proceedings of the International Conference on Management and Service Science, Wuhan, China, 24-26 August 2010.

[19] Pan, L. Display of Clothing Sales in the Network Environment. Master's Thesis, Jiangnan University, Wuxi, China, 2007.

[20] Navon, D. Forest before trees: The precedence of global features in visual perception. Cogn. Psychol. 1977, 9, 353-383.

[21] Navon, D. Do attention and decision follow perception comment on miller. J. Exp. Psychol. Hum. Percept. Perform. 1981, 7, 1175.

[22] Han, S.H. The global precedence in visual information processing. J. Chin. Psychol. Acta Psychol. Sin. 2000, 3, 337-347.

\section{Cite this article as :}

Tanmayee Tushar Parbat, Rohan Benhal, Honey Jain, Dr. Vinayak Musale, "Explore the Short Video's Technology in E-commerce in India", International Journal of Scientific Research in Computer Science, Engineering and Information Technology (IJSRCSEIT), ISSN : 2456-3307, Volume 7 Issue 6, pp. 276-284, November-December 2021. Journal URL : https://ijsrcseit.com/CSEIT217675 